\title{
Near-Miss Incidents in Obstetric Patients Admitted to an Intensive Care Unit of a Tertiary Care Center in Eastern India: A Retrospective Cohort Study
}

\author{
M Krishna Kumar ${ }^{1}$ (1) $\cdot$ Aditya Joshi $^{1} \cdot$ Monica Saraswat $^{2} \cdot$ Tony Jose $^{3} \cdot$ Rajan Kapoor $^{4} \cdot$ Madhulima Saha $^{5}$. \\ Bhupesh Kumar Goyal ${ }^{6}$
}

Received: 24 June 2021 / Accepted: 22 August 2021 / Published online: 5 September 2021

(c) Federation of Obstetric \& Gynecological Societies of India 2021

\begin{abstract}
Aim Obstetric patients presenting to the intensive care units (ICU) with or without underlying medical or surgical comorbidities can be a challenge to both the treating obstetrician and the intensivist. They occasionally present with near-miss events which if left untreated, can result in death.

Objectives To study the prevalence, indications of ICU admissions, near-miss events, and their effect on mortality in obstetric and puerperal patients.

Material \& methods We conducted a retrospective analysis of the health records of all the obstetric and puerperal patients (pregnant and until 6 weeks postpartum) admitted to our tertiary care hospital from January 2019 to December 2020. Patient demographic characteristics, obstetric, surgical, and medical conditions, acute physiology, and chronic health evaluation (APACHE) II scores, organ failures, treatment, ICU and hospital length of stay, and mortality outcomes were studied.

Results A total of 22 obstetric patients were admitted to the ICU during the above study period. Mean age was $28.7 \pm 6.24$ years, mean gestation was $34.4 \pm 6.61$ weeks, mean APACHE II score was $12.68 \pm 5.67$, median ICU length of stay was 5 days, and median duration of hospital length of stay was 10 days. The antepartum risk factors such as severe preeclampsia (27\%), antepartum bleeding (14\%), and postpartum complications like postpartum haemorrhage (33\%), sepsis with multiorgan failure (25\%) are the commonest indications that resulted in ICU admission.

Conclusion Higher APACHE II scores at the time of ICU admission, prolonged ICU, and hospital length of stay may be associated with high maternal mortality.
\end{abstract}

Keywords Near-miss events $\cdot$ Maternal mortality $\cdot$ APACHE II score

Dr. Krishna Kumar is an Assistant professor, Department of Anaesthesiology \& Critical Care, Command Hospital (EC) Kolkata -700027 India; Dr. Aditya Joshi is an Assistant professor, Department of Anaesthesiology \& Critical Care, Command Hospital (EC) Kolkata -700027 India; Dr. Monica Saraswat is an Assistant professor, Dept of Obstetrics and Gynaecology, Command Hospital (EC) Kolkata -700027 India; Dr. Tony Jose is an Professor, Dept. of Obstetrics and Gynaecology, ARMED FORCES MEDICAL COLLEGE, Pune - Maharashtra India; Dr. Rajan Kapoor is an Professor of Medicine \& Onco-Haematology, Dept. of Internal medicine, Command Hospital (EC) Kolkata -700027 India; Dr. Madhulima Saha is an Assistant professor, Dept of Obstetrics and Gynaecology, Command Hospital (EC) Kolkata -700027 India; Dr. Bhupesh Kumar Goyal is an Professor, Dept of Obstetrics and Gynaecology Command Hospital (SC) Pune-411040 India.

Extended author information available on the last page of the article

\section{Introduction}

Intensive care units of tertiary care hospitals occasionally receive critically ill pregnant patients often with or without medical and surgical comorbidities associated with the pregnancy-induced altered physiological state can be a challenge to both the treating obstetrician and intensivist. According to the World health organization (WHO), a maternal near-miss case is defined as "a woman who nearly died but survived a complication that occurred during pregnancy, childbirth or within 42 days of termination of pregnancy". In simple terms, women were considered near-miss cases when they survive life-threatening conditions (i.e. organ dysfunction) [1]. Near-miss events are important indicators for assessing maternal health in developing countries [2]. Admission to an intensive care 
unit (ICU) is defined as a unit that provides $24-\mathrm{h}$ medical and nursing supervision, mechanical ventilation, hemodynamic monitoring, dialysis support, and organ support [1]. Early intervention and vigilant monitoring in the labour room, operation theatre, postoperative period, and in the ICU with early referral to a tertiary care center can reduce maternal mortality and morbidity. We retrospectively studied the maternal cases admitted to ICU to ascertain the indications of admission, hemodynamic support, mechanical ventilation, Dialysis support, and prevalence of maternal mortality. We also tried to understand whether APACHE II scores, prolonged ICU, and hospital length of stay are predictors of increased mortality $[3,4]$.

\section{Materials and Methods}

We aimed to study the prevalence, indications of ICU admission, near-miss events, and their effect on mortality in obstetric and puerperal patients. After approval from the hospital ethics committee, a retrospective study was done based on the analysis of medical records of critically ill obstetric patients admitted to the ICU of a large tertiary care hospital in eastern India from January 2019 to December 2020. The hospital is a 950-bedded multispecialty tertiary care center with referrals mostly from service hospitals of eastern India. It has 15-bedded ICU, which is fully equipped and staffed round the clock. Critically ill obstetric patients admitted to the ICU during the above period were part of the study. These patients admitted to the ICU were either in their peripartum or postpartum period (up to 6 weeks) as per WHO near-miss criteria and were managed by both the treating obstetrician and intensivists. The data collected were patient demographics, obstetric history (gravida, para, period of gestation), antenatal comorbidities (medical or surgical history), mode of delivery (emergency/elective caesarean or vaginal), type of anaesthesia, postpartum complications resulting in ICU admission, \& foetal outcomes. The ICU-related data collected were days of mechanical ventilation, or vasopressor/dialysis support, the requirement of blood transfusion, sepsis, multiorgan failure, number of days on antibiotics. ICU and hospital length of stay (LOS) and APACHE II score were studied as predictors of maternal mortality. The timeline of the patients included in the study was either till the time of discharge from the hospital or death.

\section{Statistical analysis}

The demographic data were expressed as mean \pm standard deviation (SD) of the mean, median for continuous variables, and as frequencies and percentages for categorical variables. Comparison of quantitative variables between the study groups was done using students' $t$ test and Mann-Whitney $\mathrm{U}$ test for independent samples for parametric and nonparametric data, respectively. For comparing categorical data, the chi-square $\left(\chi^{2}\right)$ test was performed, and the fishers-exact test was used when the frequency was $<5$.

Regression analysis was done to predict the factors affecting mortality. Accuracy graphs were plotted for APACHE II scores to identify cut-offs in predicting mortality. A probability value (P-values) $<0.05$ is considered statistically significant. All statistical calculations were done using " $R$ " software 4.0.5.

\section{Results}

The hospital is a tertiary care referral center located in eastern India with a total of 1678 deliveries conducted during the period 2019-2020 of which $22(1.31 \%)$ patients required intensive care services. The data was collected retrospectively, the primary indication for ICU admission was for mechanical ventilation, hemodynamic support, extracorporeal therapy / dialysis, and intensive care monitoring. Direct obstetric causes leading to ICU admission were $86.3 \%$ and the remaining were due to secondary medical complications. The mean age at the time of ICU admission was $28.7 \pm 6.24$ years, and the mean period of gestation was $34.4 \pm 6.61$ weeks (Table 1 ).

Of the total 22 patients who were admitted to ICU, 16 (72.7\%) patients had undergone emergency caesarean section, $2(11.1 \%)$ patients underwent elective caesarean section, and $4(16.2 \%)$ were normal vaginal deliveries. Of those patients who underwent caesarean section, $66.6 \%$ were under general anaesthesia, and $33.3 \%$ were under spinal anaesthesia. There was no difference in the maternal outcomes based on the type of anaesthesia used. The median age of patients undergoing emergency $\mathrm{C}$-sections, elective $\mathrm{C}$-sections, and vaginal deliveries were 27.5, 28 years, and 29 years, respectively. Emergency C-Sects. $(72.7 \% \%)$ had a higher incidence of complications compared to elective surgeries.

The antepartum risk factors and the postpartum complications resulting in ICU admission are shown in Fig. 1: Antepartum risk factors and postpartum complications. Severe preeclampsia (27\%), antepartum haemorrhage (14\%) either due to placenta previa/ abruptio placenta, hypothyroidism and diabetes, etc. are the commonest antepartum 
Table 1 Demographic data of obstetric patients admitted to ICU

\begin{tabular}{lcll}
\hline Parameter & Mean \pm S. D & Max & Min \\
\hline Age & $28.7 \pm 6.24$ & 40 & 19 \\
Gravida & $1.95 \pm 0.844$ & 4 & 1 \\
para & $0.727 \pm 0.631$ & 2 & 0 \\
Period of gestation & $34.14 \pm 6.61$ & 39 & 10 \\
APACHE II & $12.68 \pm 5.67$ & 28 & 7 \\
\hline
\end{tabular}

risk factors. Haemorrhage (33\%), sepsis with multiorgan failure $(25 \%)$ are the commonest postpartum complications.

Two $(9 \%)$ patients had an antepartum haemorrhage, of which one patient presented with placenta previa and the second patient had placenta percreta invading into the bladder, both requiring peripartum hysterectomy following $\mathrm{C}$-section. Patient with placenta previa had massive intraoperative bleeding due to severe atonic $\mathrm{PPH}$, unresponsive to uterotonics, managed with peripartum hysterectomy, blood and component therapy, and factor VII concentrates (NovoSeven ${ }^{\circledR}$ ) along with mechanical ventilatory and vasopressor support. Patient with placenta percreta was diagnosed antenatally with MRI \& ultrasound imaging, managed with uterine artery embolization intraoperatively by interventional radiology team followed by hysterectomy soon after the C-section. Ten (45\%) patients had developed multiorgan failure due to multiple aetiologies, requiring invasive mechanical ventilation, hemodynamic monitoring, vasopressor, and dialysis support. Five (22.7\%) patients had severe sepsis with multiorgan failure. Out of four $(16.2 \%)$ patients with normal vaginal delivery who required ICU admission, two required general anaesthesia for retained placenta followed by ICU admission for unexplained hypotension, dyspnea, and pulmonary oedema in the postoperative

\begin{tabular}{|c|c|c|c|c|c|c|c|c|c|}
\hline patient_no & age & para & antenatal_complications & type_delivery & post_partum_complications & indication_Iscs & apache_ii & days_in_icu & outcomes \\
\hline 1 & 24 & 1 & placenta previa/percreta & emergency & peripartum hysterectomy & maternal & 10 & 2 & $\begin{array}{l}\text { alive \& } \\
\text { discharged }\end{array}$ \\
\hline 2 & 19 & 0 & Teenage pregnancy with fetal distress & emergency & pulmonary embolism & fetal & 10 & 5 & $\begin{array}{l}\text { alive \& } \\
\text { discharged }\end{array}$ \\
\hline 3 & 24 & 0 & severe preeclampsia & emergency & pulmonary edema with peripartum cardiomyopathy & maternal & 10 & 5 & $\begin{array}{l}\text { alive \& } \\
\text { discharged }\end{array}$ \\
\hline 4 & 38 & 1 & IHCP plus IUFD & vaginal & Acute kidney injury (AKI) & nil & 8 & 5 & $\begin{array}{l}\text { alive \& } \\
\text { discharged }\end{array}$ \\
\hline 5 & 28 & 1 & previous LSCS & elective & post partum hemorrhage & maternal & 8 & 5 & $\begin{array}{l}\text { alive \& } \\
\text { discharged }\end{array}$ \\
\hline 6 & 21 & 0 & IUFD with IUGR & vaginal & retained placenta with $\mathrm{PPH}$ & nil & 7 & 5 & $\begin{array}{l}\text { alive \& } \\
\text { discharged }\end{array}$ \\
\hline 7 & 28 & 1 & $\begin{array}{l}\text { cardiac disease(RHD severe MS and MR) with previous } \\
\text { LSCS }\end{array}$ & elective & pulmonary edema. & maternal & 10 & 3 & $\begin{array}{l}\text { alive \& } \\
\text { discharged }\end{array}$ \\
\hline 8 & 29 & 1 & severe preeclampsia with IUGR & emergency & Partial HELLP with Impending eclampsia & maternal & 12 & 5 & $\begin{array}{l}\text { alive \& } \\
\text { discharged }\end{array}$ \\
\hline 9 & 40 & 1 & previous LSCS in labour & emergency & post partum hemorrhage & maternal & 8 & 4 & $\begin{array}{l}\text { alive \& } \\
\text { discharged }\end{array}$ \\
\hline 10 & 33 & 1 & placenta previa/increta & emergency & peripartum hysterectomy & maternal & 10 & 4 & $\begin{array}{l}\text { alive \& } \\
\text { discharged }\end{array}$ \\
\hline 11 & 25 & 1 & severe preeclampsia with non progess of labour & emergency & PPH with DIC and eclampsia & maternal & 29 & 1 & dead \\
\hline 12 & 27 & 0 & abruptio placenta & emergency & shock with DIC & maternal & 12 & 5 & $\begin{array}{l}\text { alive \& } \\
\text { discharged }\end{array}$ \\
\hline 13 & 20 & 0 & severe preeclampsia & emergency & Partial HELLP with uncontrolled hypertension & maternal & 12 & 4 & $\begin{array}{l}\text { alive \& } \\
\text { discharged }\end{array}$ \\
\hline 14 & 29 & 0 & twin pregnancy with preterm labour & vaginal & Retained placenta with peripartum cardiomyopathy & maternal & 15 & 4 & $\begin{array}{l}\text { alive \& } \\
\text { discharged }\end{array}$ \\
\hline 15 & 28 & 1 & previous LSCS in labour & emergency & Pulmonary edema & maternal & 10 & 4 & $\begin{array}{l}\text { alive \& } \\
\text { discharged }\end{array}$ \\
\hline 16 & 38 & 1 & severe preeclampsia & emergency & impending eclampsia & maternal & 10 & 5 & $\begin{array}{l}\text { alive \& } \\
\text { discharged }\end{array}$ \\
\hline 17 & 34 & 1 & acute pancreatitis & emergency & sepsis with multiorgan failure & fetal & 29 & 35 & dead \\
\hline 18 & 29 & 1 & acute fatty liver of pregnancy & emergency & sepsis with DIC & maternal & 15 & 7 & $\begin{array}{l}\text { alive \& } \\
\text { discharged }\end{array}$ \\
\hline 19 & 31 & 0 & malaria & vaginal & sepsis with multiorgan failure & maternal & 17 & 7 & $\begin{array}{l}\text { alive \& } \\
\text { discharged }\end{array}$ \\
\hline 20 & 23 & 0 & severe preeclampsia with IUGR & emergency & $\begin{array}{l}\text { uncontrolled hypertension with Impending } \\
\text { eclampsia }\end{array}$ & maternal & 12 & 5 & $\begin{array}{l}\text { alive \& } \\
\text { discharged }\end{array}$ \\
\hline 21 & 40 & 2 & ovarian Ectopic pregnancy, obesity & emergency & hemoperitoneum with shock & maternal & 8 & 3 & $\begin{array}{l}\text { alive \& } \\
\text { discharged }\end{array}$ \\
\hline 22 & 25 & 2 & obesity & emergency & $\begin{array}{l}\text { sepsis secondary to Appendicitis withcecal } \\
\text { perforation }\end{array}$ & maternal & 28 & 21 & dead \\
\hline
\end{tabular}

Fig. 1 Antepartum risk factors and postpartum complications 
period, which was diagnosed as peripartum cardiomyopathy by using point of care bedside $2 \mathrm{D}$ echocardiography and cardiac biomarkers.

Invasive hemodynamic monitoring was required in $91 \%$ of patients admitted to the intensive care unit. Ten $(45.5 \%)$ patients had developed multiorgan failure requiring mechanical ventilation, vasopressor support, antibiotic therapy, and dialysis. Patients with acute fatty liver of pregnancy (AFLP) had developed disseminated intravascular coagulation (DIC), requiring multiple blood transfusions, vasopressor support, and mechanical ventilation. Three patients of the $22(13.63 \%)$ that were admitted to the ICU had died in the peripartum period, one with severe preeclampsia, DIC, and postpartum eclampsia, in the immediate postoperative period and sustained a sudden cardiac arrest probably due to secondary intracerebral haemorrhage. The second patient presented with severe acute pancreatitis underwent emergency $\mathrm{C}$-section for foetal distress under general anaesthesia, had developed sepsis with multi-organ failure, and had died after 35 days as sequelae to pancreatitis, and the third was a referred patient with intestinal perforation, peritonitis, and severe sepsis. She was taken up for emergency laparotomy and had a stormy postoperative period with cytokine storm managed with broad-spectrum antibiotic therapy, mechanical ventilation, vasopressor support, cytosorb therapy, and hemodialysis. She succumbed after 21 days in the intensive care unit due to multidrug-resistant ventilator-associated pneumonia, critical illness myopathy, neuropathy, and multiorgan failure leading to death.

The median ICU length of stay was 5 days and the median duration of hospital length stay was 10 days. Patients with sepsis and multiorgan failure had a longer length of ICU stay compared to other postpartum complications Fig. 2: Median ICU length of stay.

The patient with severe pancreatitis had a more protracted illness with sepsis and multi-organ failure resulting in increased ICU length of stay. It was also observed that there was a higher incidence of acute kidney injury (AKI), requiring hemodialysis in these patients. APACHE II score was used for predicting maternal mortality, with the use of accuracy curves, and a score of more than 22.5 predicted a 100\% mortality Fig. 3: Accuracy curve of APACHE II score in our study. The mean APACHE II score at the time of ICU admission was $12.68 \pm 5.67$, and there was a direct correlation in $54.5 \%$ of patients with higher APACHE II values on the duration of antibiotics, and requirement of blood transfusion and component therapy.

Postpartum haemorrhage, acute fatty liver of pregnancy, acute pancreatitis, and sepsis had a higher requirement of blood transfusion, and prolonged vasopressor, and mechanical ventilatory support. Eighteen (81.8\%) patients had live births while the rest were stillbirths/Intrauterine deaths (IUD). There were 1678 deliveries conducted in the institution, of which $22(1.31 \%)$ patients required ICU admission and, 3 had died during the study period with a maternal mortality rate of 1.78/1000. The outcomes are shown in Table 2 .

\section{Discussion}

In our study majority of the women admitted to the ICU were in the age group 25-30 years (31.8\%) followed by 20-25 years $(27.2 \%)$, this could be probably due to a large number of pregnancies and deliveries were in this age group [5]. Term pregnancies were $45.4 \%$ in our study,

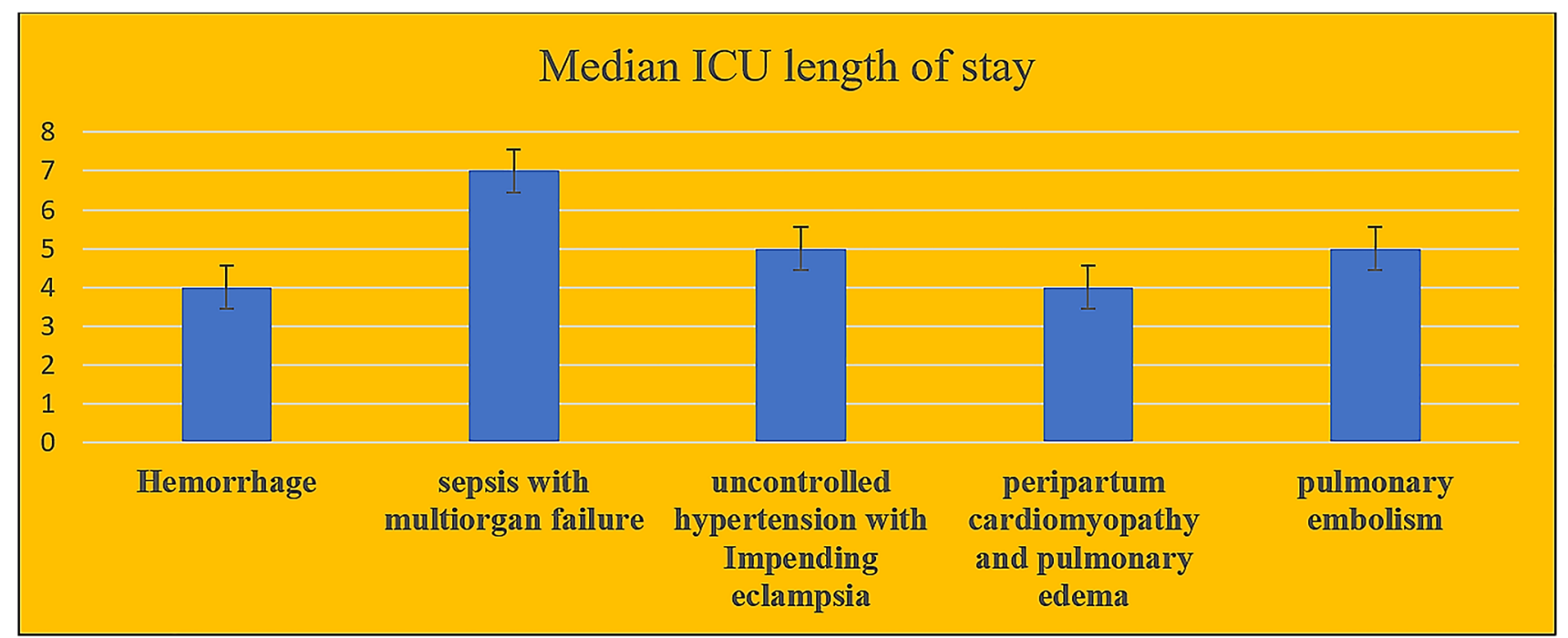

Fig. 2 Median ICU length of stay 
Fig. 3 Accuracy curve of APACHE II score

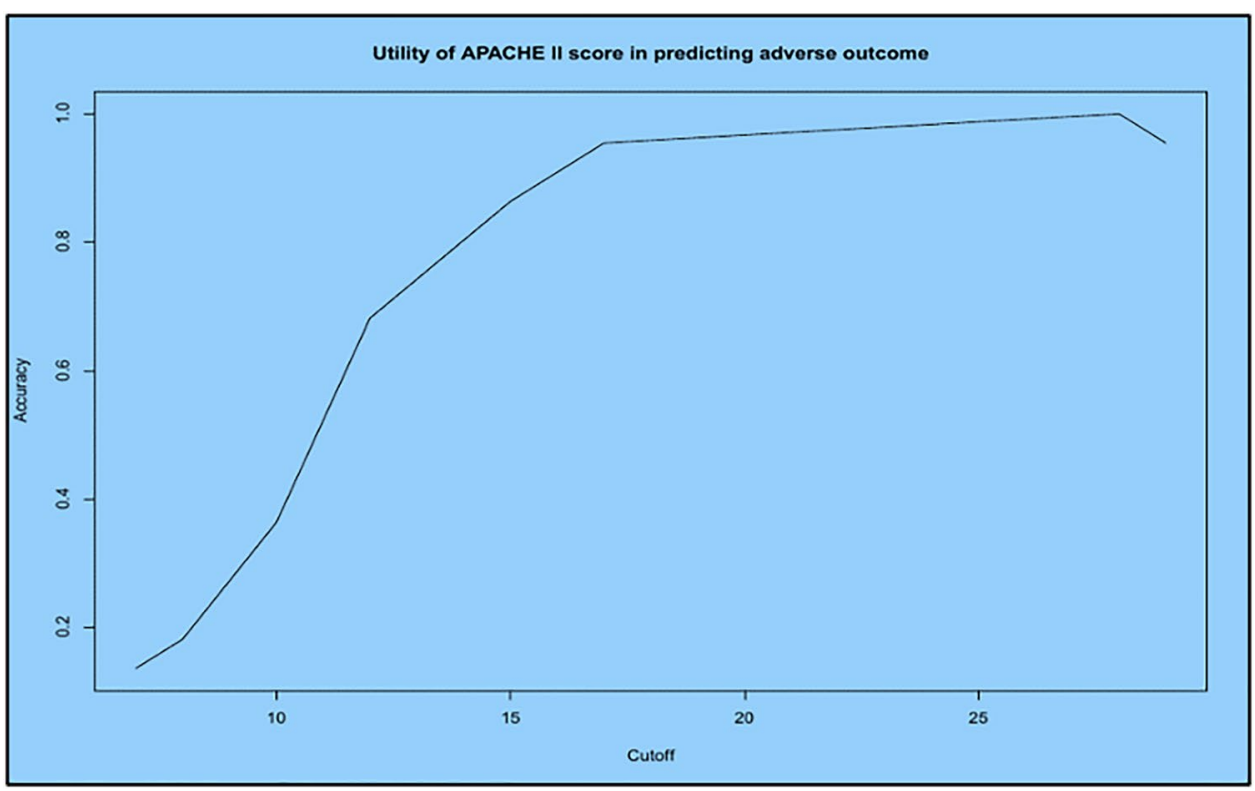

Table 2 maternal outcomes

\begin{tabular}{llll}
\hline Type of delivery & \multicolumn{2}{l}{ Outcomes } & Total \\
\cline { 2 - 3 } & $\begin{array}{l}\text { Alive \& dis- } \\
\text { charged }\end{array}$ & Dead & \\
\hline Elective C-section & 2 & 0 & 2 \\
$\begin{array}{l}\text { Emergency } \\
\text { C-section }\end{array}$ & 13 & 3 & 16 \\
vaginal & 4 & 0 & 4 \\
Total & 19 & 3 & 22 \\
$\chi^{2}=1.303 \cdot d f=2 \cdot$ Cramer's $V=0.243 \cdot$ Fisher's $p=1.000$ & \\
\hline
\end{tabular}

and the remaining $54.6 \%$ were preterm pregnancies. An increased risk of neonatal deaths was observed in preterm pregnancies which were similar to the other studies [6]. The majority (90.9\%) of the patients were booked cases. Multigravidae (68.1\%) with high parity in our study group were observed to have more complications which are comparable to other studies [7, 8]. Among the ICU admissions, $77.27 \%$ had postoperative complications either due to bleeding diathesis, respiratory involvement (Hypoxia), cardiac instability, sepsis, or pulmonary oedema. The ratio of near-miss to maternal mortality in our study was 7.33:1 i.e. for every 7 near-miss admissions to the ICU one maternal mortality was seen. The incidence of maternal nearmiss in our study was 13.11 per 1000 deliveries.

Postpartum haemorrhage (33\%) was the commonest complication that resulted in ICU admission, which was higher than the global studies [9]. Evidence from various clinical trials has shown that the incidence of postpartum bleeding can be decreased with the routine use of intravenous antifibrinolytic drugs, such as tranexamic acid in the perioperative period in both emergency and elective $\mathrm{C}$-sections, which was a common clinical practice at our center [10]. Two patients required factor VII for major $\mathrm{PPH}$, apart from surgical haemostasis, blood, and component therapy [11].

Sepsis and multiorgan failure (25\%) was the second commonest cause of ICU admission in our study which was also higher compared to other available studies [12]. Goaldirected resuscitation based on surviving sepsis guidelines was practiced in our institution and was shown to have a proven benefit $[13,14]$. Severe preeclampsia contributed to $21 \%$ of the ICU admissions in our hospital $[15,16]$.

Early detection and better blood pressure control with a prompt referral of preeclampsia cases to tertiary centers and timely termination of these pregnancies can reduce the complications and near-miss events. Peripartum cardiomyopathy was seen in $17 \%$ of the ICU admissions, the incidence was also similar to other studies [17]. These patients were managed with diuretics, aldosterone receptor antagonists, ACE inhibitors/ angiotensin receptor blockers along with or without invasive/ non-invasive mechanical ventilation. The incidence of maternal mortality in our study was 1.78 for every 1000 deliveries performed which was far less than the national Figs. [5].

We had used APACHE II over other scoring systems i.e. sequential organ failure assessment (SOFA), simplified acute physiology score (SAPS) II, and mortality prediction models (MPM), as we had a heterogenous obstetric population admitted to the ICU and no single scoring system was accurate in predicting the mortality. All the parameters of the APACHE II scoring system were readily available at the time of admission to the ICU and the staff was familiar. Patients admitted to the ICU in our study were mostly 
due to haemorrhagic complications and APACHE II scoring did better over other scoring systems [18]. Although the APACHE II score had overestimated in predicting maternal mortality in many other studies, we had used this scoring system, with the accuracy curves in predicting mortality, and a score of $>22.5$, when associated with increased duration of stay in ICU was shown to be consistent in predicting maternal mortality [19]. An updated version of the APACHE II score had shown to have similar outcomes in predicting maternal mortality [20]. The use of Obstetric early warning scoring systems is also useful in predicting mortality within the first $24 \mathrm{~h}$ of admission in the ICU, but there were no head-to-head trials done comparing with more commonly used scoring systems [21]. Multiple organ dysfunction scores (MODS) and SOFA scores did well in predicting mortality in obstetric sepsis patients [4]. Though APACHE II scoring systems are older it is still clinically relevant in multiple other disease conditions.

\section{Limitations}

This study was limited by its small sample size and retrospective nature. Multicentric prospective trials are needed to ascertain whether APACHE II score when combined with ICU length of stay predicts maternal mortality better when compared to other scoring systems. An obstetric-specific scoring system must be designed to predict maternal mortality in the ICU.

\section{Conclusions}

Early identification of the near-miss events based on WHO maternal near-miss tool/ criteria, vigilant monitoring, and timely intervention with good communication \& teamwork between obstetric, intensive care teams, and sub-specialties like obstetric medicine, clinical haematology, interventional radiology, clinical pathology, and microbiological services can help in reducing maternal mortality and morbidity in critically ill obstetric patients. All obstetric, emergency medicine and anaesthesia residents should be well versed with WHO near-miss criteria in pregnant women. The limitations that need to be addressed in developing countries are nurse to patient ratio, designated early /electronic warning systems, massive transfusion protocols, visco-elastic testing, adequate resources, etc.

Authors' contributions Directly involved in collecting, editing, and analysis of the data.

Funding Not Applicable. No external source of financing.

\section{Declarations}

Conflict of interest The authors declare no conflicts of interest.

Consent to Participate Informed Consent taken from all the participants.

Ethical approval Institutional Ethical committee approval is taken.

Human and Animal Rights No Animals were involved in the study. It is a retrospective study.

Data Availability Available with the corresponding author.

\section{References}

1. World Health Organization. The WHO Near-Miss approach for Maternal Health. World Heal Organ [Internet]. 2011;1-34. Available from: www.who.int/reproductivehealth\%0Ahttp://apps.who. int/iris/bitstream/10665/44692/1/9789241502221_eng.pdf

2. England N, Madill J, Metcalfe A, Magee L, Cooper S, Salmon C, et al. Monitoring maternal near miss/severe maternal morbidity: A systematic review of global practices. PLoS One [Internet]. 2020;15(5):1-14. Available from: http://dx.doi.org/https://doi.org/ 10.1371/journal.pone.0233697

3. Sodhi K, Bansal V, Shrivastava A, Kumar M, Bansal N. Predictors of mortality in critically ill obstetric patients in a tertiary care intensive care unit: A prospective 18 months study. J Obstet Anaesth Crit Care. 2018;8(2):73.

4. Aarvold ABR, Ryan HM, Magee LA, Von Dadelszen P, Fjell C, Walley KR. Multiple organ dysfunction score is superior to the obstetric-specific sepsis in obstetrics score in predicting mortality in septic obstetric patients. Crit Care Med. 2017;45(1):e49-57.

5. Office of the Registrar General I. Special Bulletin on Maternal Mortality in India 2016-18. Sample Regist Syst. 2020;(July):1-4.

6. Machado LC, Passini R, Rosa IR, Carvalho HB. European Journal of Obstetrics \& Gynecology and Reproductive Biology Neonatal outcomes of late preterm and early term birth [Internet]. Vol. 179, Elsevier Ireland Ltd. 2014. p. 204-8. Available from: http:// dx.doi.org/https://doi.org/10.1016/j.ejogrb.2014.04.042

7. Sonneveldt E, Decormier Plosky W, Stover J. Linking high parity and maternal and child mortality: What is the impact of lower health services coverage among higher order births? BMC Public Health. 2013;13(SUPPL.3).

8. Khumanthem PD, Chanam MS, Samjetshabam RD. Maternal mortality and its causes in a tertiary center. J Obstet Gynecol India. 2012;62(2):168-71.

9. Say L, Chou D, Gemmill A, Tunçalp Ö, Moller AB, Daniels J, et al. Global causes of maternal death: A WHO systematic analysis. Lancet Glob Heal. 2014;2(6):323-33.

10. Shakur H, Roberts I, Fawole B, Chaudhri R, El-Sheikh M, Akintan A, et al. Effect of early tranexamic acid administration on mortality, hysterectomy, and other morbidities in women with post-partum haemorrhage (WOMAN): an international, randomised, double-blind, placebo-controlled trial. Lancet. 2017;389(10084):2105-16.

11. No GG. Prevention and Management of Postpartum Haemorrhage: Green-top Guideline No. 52. BJOG An Int J Obstet Gynaecol. 2017;124(5):e106-49.

12. Acosta CD, Harrison DA, Rowan K, Lucas DN, Kurinczuk JJ, Knight M. Maternal morbidity and mortality from severe sepsis: a national cohort study. BMJ Open. 2016;6(8):e012323. 
13. Levy MM, Evans LE, Rhodes A. The Surviving Sepsis Campaign Bundle: 2018 update. Intensive Care Med [Internet]. 2018;44(6):925-8. Available from: https://doi.org/10.1007/ s00134-018-5085-0

14. World Health Organization. Statement on Maternal Sepsis Sepsis: a leading cause of maternal deaths. Dep Reprod Heal Res World Heal Organ [Internet]. 2017;1-4. Available from: http://apps.who. int/iris/bitstream/10665/254608/1/WHO-RHR-17.02-eng.pdf

15. Chhabra P. Maternal near miss: An indicator for maternal health and maternal care. Indian J Community Med. 2014;39(3):132-7.

16. Chhabra P, Guleria K, Bhasin SK, Kumari K, Singh S, Lukhmana S. Severe maternal morbidity and maternal near miss in a tertiary hospital of Delhi. Natl Med J India. 2019;32(5):270-6.

17. Isogai $\mathrm{T}$, Kamiya $\mathrm{CA}$. Worldwide incidence of peripartum cardiomyopathy and overall maternal mortality. Int Heart J. 2019;60(3):503-11.

18. Oliveira-Neto AF, Parpinelli MA, Costa ML, Souza RT, Ribeiro do Valle C, Sousa MH, et al. Prediction of Severe Maternal Outcome Among Pregnant and Puerperal Women in Obstetric ICU. Vol. 47, Critical care medicine. 2019. p. e136-43.

19. Ryan HM, Sharma S, Magee LA, Ansermino JM, MacDonell $\mathrm{K}$, Payne BA, et al. The Usefulness of the APACHE II Score in Obstetric Critical Care: A Structured Review. J Obstet Gynaecol Canada [Internet]. 2016;38(10):909-18. Available from: http:// dx.doi.org/https://doi.org/10.1016/j.jogc.2016.06.013

20. Paternina-Caicedo AJ, Rojas-Suarez JA, Dueñas-Castel C, Miranda-Quintero JE, Bourjeily G. Mortality risk prediction with an updated acute physiology and chronic health evaluation II score in critically ill obstetric patients: A cohort study. Vol. 30, Journal of Intensive Care Medicine. 2015. p. 97-102.

21. Paternina-Caicedo A, Miranda J, Bourjeily G, Levinson A, Dueñas C, Bello-Muñoz C, et al. Performance of the Obstetric Early Warning Score in critically ill patients for the prediction of maternal death. Vol. 216, American Journal of Obstetrics and Gynecology. 2017. p. 58.e1-58.e8.
Publisher's Note Springer Nature remains neutral with regard to jurisdictional claims in published maps and institutional affiliations.

\section{About the Author}

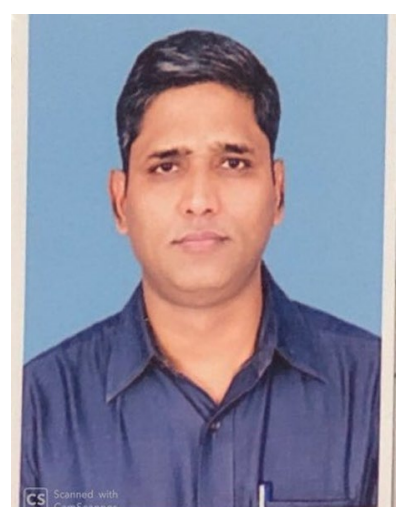

Krishna Kumar. M Classified Spl (Anaesthesiology \& critical care) Working as Asst. Professor in the Dept. of Anaesthesiology and critical care Command Hospital Eastern command Kolkata-700027 since 16 July 2018. MBBS (Feb 2003) Kasturba Medical College, Mangalore Manipal universityPGDMLS (Postgraduate diploma in medico-legal systems) from Symbiosis institute of health sciences -2006.M.D (Anaesthesiology) 2007- 2010 from Army Hospital (R\& R) Delhi University. New Delhi-110010DNB (Anaesthesiology) 2011- National Board of Examinations New Delhi.PDF (Post-Doctoral fellowship) 2016-18 in Critical care medicine from Christian Medical College (CMC), Vellore (TN). IDCCM (Indian Diploma in Critical care Medicine) from CMC Vellore 2018.EDIC (European Diploma in Intensive care Medicine)-CMC Vellore 2018 .

\section{Authors and Affiliations}

\section{Krishna Kumar ${ }^{1}$ D $\cdot$ Aditya Joshi $^{1} \cdot$ Monica Saraswat ${ }^{2} \cdot$ Tony Jose $^{3} \cdot$ Rajan Kapoor $^{4} \cdot$ Madhulima Saha $^{5}$. Bhupesh Kumar Goyal ${ }^{6}$}

M Krishna Kumar

krishnakm312@gmail.com

Aditya Joshi

majoraditya@gmail.com

Monica Saraswat

Monicasunit@gmail.com

Tony Jose

oncotango@gmail.com

Rajan Kapoor

majrkapoor@gmail.com

Madhulima Saha

madhulima.saha@gmail.com

Bhupesh Kumar Goyal

bkgnona@gmail.com
1 Assistant Professor Department of Anaesthesiology \& Critical Care, Command Hospital (EC), Kolkata 700027, India

2 Assistant Professor Dept of Obstetrics and Gynaecology, Command Hospital (EC), Kolkata 700027, India

3 Professor Dept. of Obstetrics and Gynaecology, ARMED FORCES MEDICAL COLLEGE, Pune, Maharashtra 411040, India

4 Professor Dept. of Internal Medicine, Command Hospital (EC), Kolkata 700027, India

5 Assistant Professor Dept of Obstetrics and Gynaecology, Command Hospital (EC) , Kolkata 700027, India

6 Professor Dept of Obstetrics and Gynaecology Command Hospital (SC), Pune 411040, India 